\title{
COMPONENT SUPPLY MODEL FOR REPAIR ACTIVITIES NETWORK UNDER CONDITIONS OF PROBABILISTIC INDEFINITENESS
}

\author{
Stroganov V.Yu., Faddeeva E.Yu., Sakun B.V., \\ Satyshev S.N.
}

This article contains the systematization of the major production functions of repair activities network and the list of planning and control functions, which are described in the form of business processes $(B P)$. Simulation model for analysis of the delivery effectiveness of components under conditions of probabilistic uncertainty was proposed. It has been shown that a significant portion of the total number of business processes is represented by the management and planning of the parts and components movement. Questions of construction of experimental design techniques on the simulation model in the conditions of non-stationarity were considered.

Keywords: repair; delivery; transportation; planning; inventory management; simulation modelling.

\section{Introduction}

The widespread application of advances in new information technologies requires the improvement of decision-making support systems in the field of enterprise management based on a powerful hardware and software base [1]. Acting under conditions of market economy the principle of self-financing requires providing of the company's interest in a realistic assessment of components transportation costs in the production network of repair activities [8-10]. The structure of the transport link in the repair activities network should be flexible 
enough to ensure frequent and 24/7 delivery of goods in order to maintain the rhythm of the production cycle $[11,12]$. For the systematic and balanced development of any business, especially for large repair activities that provide transportation across the region, it is necessary to introduce new technological and technical solutions, information and telecommunication technologies, new forms of management solutions, development and implementation of methods for rapid collection and analysis of survey results during inflow of component orders $[10,13,14]$.

\section{Problem statement}

In general, the transport component of the repair activity network with geographically distributed structure can be formalized in the form of a weighted graph [11]:

$$
G=<\left\{W_{\mathrm{w}}: \mathrm{i}=1 . . I_{\mathrm{o}}\right\},\left\{E_{\mathrm{j}, \mathrm{j}}: \mathrm{i}, \mathrm{j}=1 . . I\right\}>,
$$

where: $\left\{W_{\mathrm{i}}\right\}$ - the set of graph nodes corresponding to the production sites of repair activity; $\left\{E_{\mathrm{j}, \mathrm{j}}\right\}$ - set of arcs of the graph $\mathrm{G}$, which define the intensity of the flows on the component transportation in the form of distribution $\mathbf{P}=\left\{P_{\mathrm{j}, \mathrm{j}}\right\}$. According to annual data, the statistical analysis of the needs of various component categories was conducted for the purpose of the simulation model parameterization (figure 1).

Indeed, for category A and B the common share was about 20\%, while for category D - more than $60 \%$. More uniform situation was observed in groups of components.

Thus, the replacement of hydraulics was more than $20 \%$, of engine parts $-16 \%$, of units and chassis together - about $11 \%$, etc. In terms of supplying companies out of 25 thousand obtained components were HITACHI (11721 pcs.) and FIAT-HITACHI (3601 pcs.), which accounts for over than half of all deliveries.

The joint distribution of components in categories and groups is represented in Table 1. 


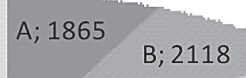

C; 5823

D; 15515

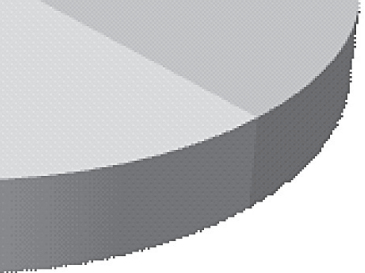

Fig. 1. Component distribution diagrams by categories

One of the objectives is aimed at modelling the delivery of components for the circular route, the general scheme of which is shown in Figure 2. Suppose we have N sites of repair activity. At each site there is a need for a random amount of components from another $\xi_{\mathrm{n}}$ (Poisson distribution $P_{k}=\sum_{i=0}^{k} \frac{e^{\lambda} \lambda^{i}}{i !}$ is anticipated in the operation). The number of intermediate sections at movement of each component position is also determined by a random variable $h$ with parameter $b$ (independent from the binomial distribution) [2]:

$$
\left.P_{k}=\sum_{i=0}^{k}\left(\begin{array}{c}
N \\
i
\end{array}\right) p^{i}(1-p)^{N-i}\right)
$$

Table 1.

The ordered quantity of components of different categories

\begin{tabular}{|l|c|c|c|c|c|}
\hline Amount per field $Z_{\text {com }}$ & \multicolumn{5}{|c|}{ ABCD } \\
\hline Group & A & B & C & D & Total \\
\hline Machinery & 31 & 75 & 247 & 547 & 900 \\
\hline Hydraulics & 76 & 342 & 1460 & 2522 & 4400 \\
\hline Motor & 122 & 275 & 782 & 2269 & 3448 \\
\hline Buckets & 5 & 31 & 102 & 163 & 301 \\
\hline Oils & 56 & 32 & 51 & 107 & 246 \\
\hline Implements & 35 & 94 & 389 & 840 & 1358 \\
\hline
\end{tabular}


End of the Table 1.

\begin{tabular}{|l|c|c|c|c|c|}
\hline Others & 390 & 511 & 1459 & 4453 & 6813 \\
\hline Spare parts service & 64 & 36 & 58 & 103 & 261 \\
\hline Filters & 611 & 227 & 248 & 487 & 1573 \\
\hline Chassis & 227 & 227 & 453 & 595 & 1502 \\
\hline Electrical engineering & 17 & 44 & 139 & 451 & 651 \\
\hline Grand total & 1634 & 1894 & 5388 & 12537 & 21453 \\
\hline
\end{tabular}
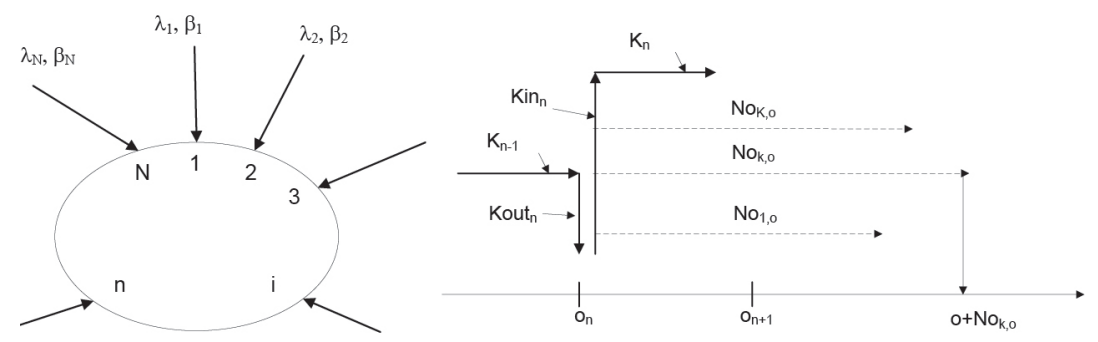

Fig. 2. Parameterization model scheme by circular route

The first task of modelling is to generate the sample path simulation of random processes of the loaded (Kin), unloaded (Kout) and the remaining amount $(\mathrm{K})$ of components. As the timeline the serial numbers of sites that define the transport facility route are used.

As initial conditions the following values $\operatorname{Kin}_{\mathrm{n}}=0, K o u t_{\mathrm{n}}=0, K_{\mathrm{n}}=0$ are chosen.

At each site the process of loading/unloading of components is modelled, which is taken place by the scheme:

1. The component unloading - Kout $_{\mathrm{n}}$ (calculated in the previous steps).

2. Playing a number of embedded parts with the Poisson distribution $\left(\operatorname{Kin}_{\mathrm{n}}=\boldsymbol{r p o i s}\left(1,1_{\mathrm{n}}\right)\right)$.

3. Calculating the number of components remaining in the transport facility:

$$
K_{\mathrm{n}}:=K_{\mathrm{n}-1}-\text { Kout }_{\mathrm{n}}+\text { Kin }_{\mathrm{n}}:
$$

4. For each loaded component the number of intermediate sections is taken place by the binomial distribution $N o=\operatorname{rbinom}(1, N, \mathrm{~m})$. Fur- 
ther, the processes merge in a single cycle of this route with their reference to the numbers of sites.

The interest in this case is the problem of stationary process estimating [6-8]. To solve it, you can exclude the first few cycles, and then combine the remaining for statistical processing and subsequent evaluation of the integral characteristics $[3,4]$.

The initial state of the model greatly influences the stationary path (Figure 3a). The graphs show that in the first cycle (the initial state of empty transport facility) of circular route there is a clearly non-stationary process.

A more detailed analysis is shown in Table 2. It is evident that the initial stage represents the growth of the average value during the variance fall. Furthermore, the skewness of the first cycle is clearly different from other cycles.

Built autocorrelation function of the vehicle load process (Figure 3b) suggests the possibility of a sufficiently accurate forecast in view of inertial nature at an early stage.

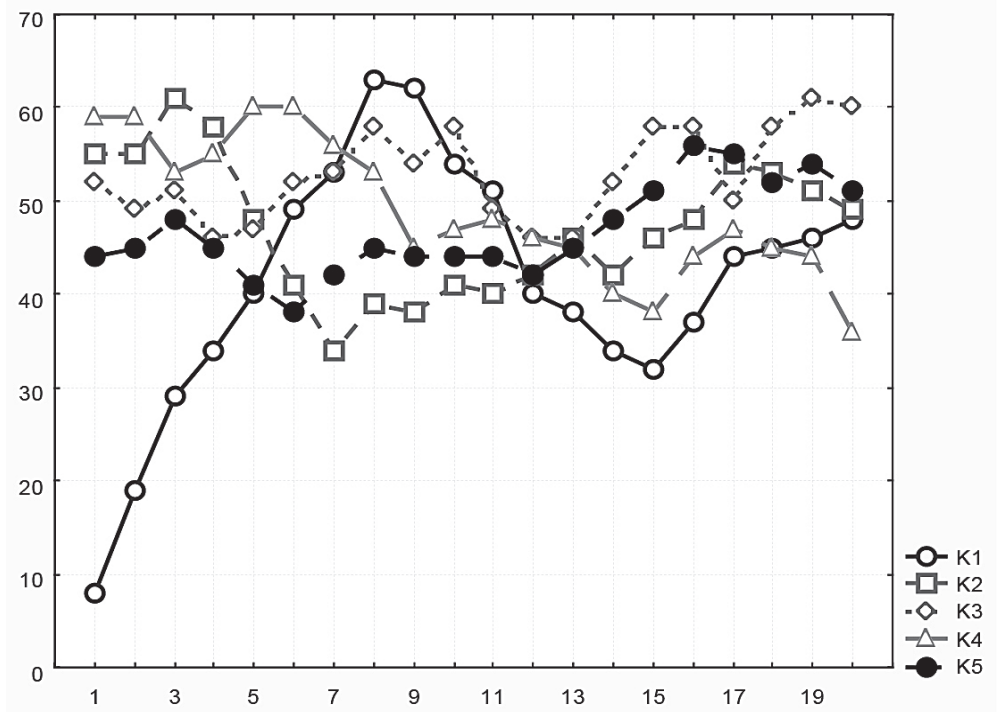




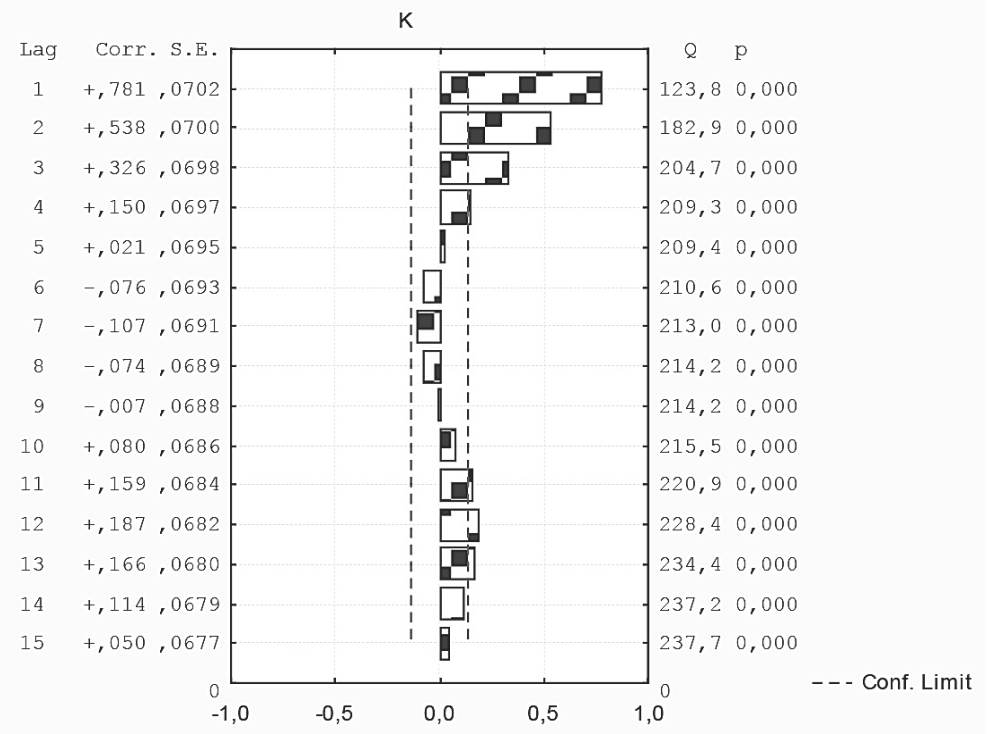

a) Vehicle workload b) Process autocorrelation

Fig. 3.

Table 2.

Descriptive statistics of component supply cycles

\begin{tabular}{|c|c|c|c|c|c|c|c|c|c|c|}
\hline \multirow{2}{*}{$\begin{array}{c}\text { Vari- } \\
\text { able }\end{array}$} & \multicolumn{10}{|c|}{ Descriptive adjectives } \\
\cline { 2 - 12 } & $\begin{array}{c}\text { Aver- } \\
\text { age }\end{array}$ & $\begin{array}{c}\text { Confi- } \\
\text { dence } \\
\text { interval } \\
-95,000\end{array}$ & $\begin{array}{c}\text { Confi- } \\
\text { dence } \\
\text { interval } \\
+95,000\end{array}$ & $\begin{array}{c}\text { Me- } \\
\text { dian }\end{array}$ & $\begin{array}{c}\text { Mini- } \\
\text { mum }\end{array}$ & $\begin{array}{c}\text { Maxi- } \\
\text { mum }\end{array}$ & $\begin{array}{c}\text { Vari- } \\
\text { ance }\end{array}$ & $\begin{array}{c}\text { Stan- } \\
\text { devia- } \\
\text { dion }\end{array}$ & $\begin{array}{c}\text { Stan- } \\
\text { dard } \\
\text { error }\end{array}$ & $\begin{array}{c}\text { Skew- } \\
\text { ness }\end{array}$ \\
\hline K1 & 41,30 & 35,01 & 47,58 & 42,00 & 8,00 & 63,00 & 180,11 & 13,42 & 3,00 & $-0,65$ \\
\hline K2 & 47,05 & 43,58 & 50,51 & 47,00 & 34,00 & 61,00 & 54,68 & 7,39 & 1,65 & 0,16 \\
\hline K3 & 52,90 & 50,57 & 55,22 & 52,00 & 46,00 & 61,00 & 24,72 & 4,97 & 1,11 & 0,10 \\
\hline K4 & 49,00 & 45.52 & 52,47 & 47,00 & 36,00 & 60,00 & 55,05 & 7,42 & 1,65 & 0,08 \\
\hline K5 & 46,70 & 44,37 & 49,02 & 45,00 & 38,00 & 56,00 & 24,74 & 4,97 & 1,11 & 0,44 \\
\hline K6 & 50.05 & 46,48 & 53,61 & 60,00 & 38,00 & 63,00 & 57,94 & 7,61 & 1,70 & 0,20 \\
\hline K7 & 41,70 & 39,69 & 43,70 & 42,00 & 34,00 & 49,00 & 18,32 & 4,28 & 0,95 & 0,05 \\
\hline
\end{tabular}

The developed simulation model allows you to load the vehicle on an unlimited capacity for circular route. Figure 4 shows a load di- 
agram for the input streams, where on the objects 5 and 12 there is an increased flow of loading components.

The diagram shows the cyclical nature of the vehicle load, which is determined by the structure of the input streams on the movement of certain groups of components. Such information provides the basis for calculating the required number of the vehicles under probabilistic indefiniteness.

In terms of evaluation of non-stationary processes during the work, the trend concept $G(t)=\boldsymbol{M} \xi\left(t \mid S_{0}\right)$ of conditionally non-stationary process is used as the basic models, where $S_{0}$ - is initial simulation conditions.

Thus, the process is inertia-free when $\forall t>0 G(t)=0$. This condition is satisfied only when the sample values are independent, and their mathematical expectation - unbiased functional estimator. The process is inertial when $\exists \mathrm{t}^{*}>0: G\left(t^{*}\right) \neq 0$ and $\lim _{t \rightarrow \infty} G(t)=0$.

Swing diagram (Spreadsheet2. sta $10 v^{*} 200 \mathrm{c}$ )

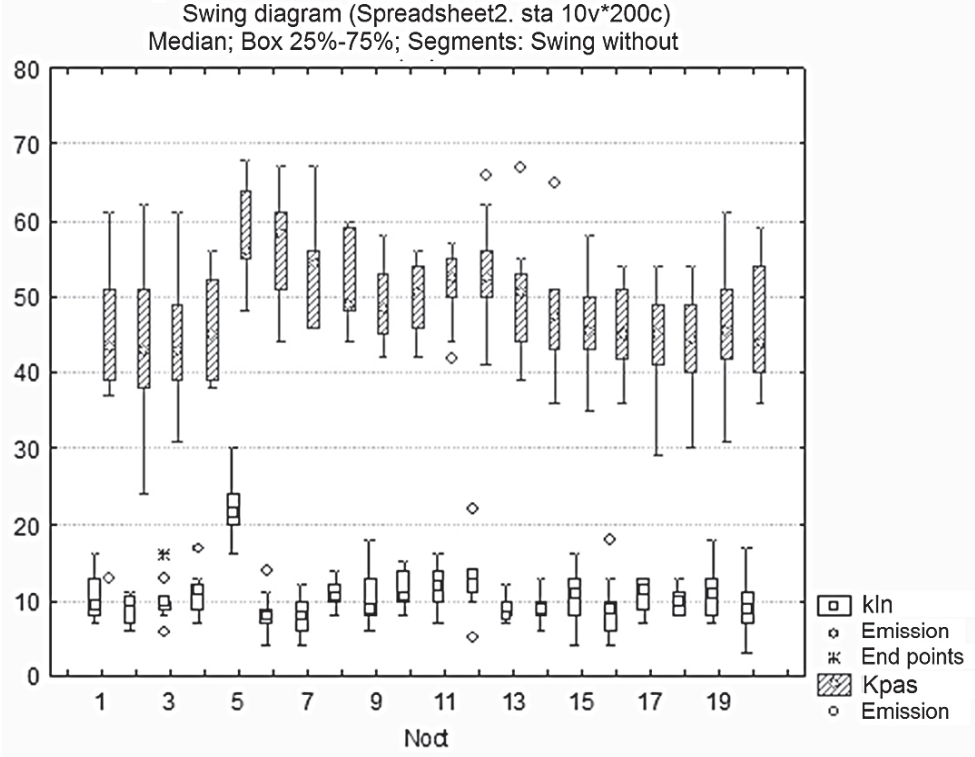

Fig. 4. Diagram of vehicle capacity on circular route 
The condition of the limit existence is performed because of the existence of a stationary test process distribution. It is shown that the monotone trends are rather typical for the simulation of output delivery processes under probabilistic indefiniteness $[4,5]$.

Monotony properties make it possible to investigate the quality characteristics of the processes, which include the stochastic procedure between random variables $\xi_{1}$ and $\xi_{2}$, which is determined by the ratio

$$
\xi_{1} \prec \xi_{2} \Leftrightarrow \Phi_{1} \prec \Phi_{2}, \Phi_{1} \prec \Phi_{2} \Leftrightarrow \forall x, \Phi_{1}(x) \geq \Phi_{2}(x) .
$$

where "२"- stochastic order ratio; $\Phi_{1}, \Phi_{2}-$ distribution functions of random variables $\xi_{1}$ and $\xi_{2}$.

The planning procedure of simulation model experiment in the conditions of non-stationarity is provided below. The described steps of simulation can be represented in the form of static structure diagrams of simulation classes and dynamic charts of activity, conditions, sequence and interaction diagrams.

As an experiment plan for the simulation model it is proposed to use rotatable design, in which the optimality criterion is the condition $\sigma_{y}^{2}=$ const at the same distance of experiment points from the center.

If there are two-factor plans, the plans are examples of rotatable plans represented by the vertices and at least one central point of any (n-1)-dimensional regular polygon, which can be inscribed in a circle [12].

Uniform location of points on the sphere results in degenerate matrices.

To eliminate the degeneracy the zero-radius sphere with several central points is used.

Thus, the estimated coefficients are calculated on the basis of the following ratios [16]:

$$
\begin{gathered}
b_{0}=\frac{A}{N}\left[2 \lambda^{2}(n+2) \sum_{j=1}^{N} x_{j, 0} \bar{y}_{j}-2 \lambda C \sum_{i=1}^{n} \sum_{j=1}^{N} x_{j, i} \bar{x}_{j}\right] \\
b_{i i}=\frac{A}{N}\left\{C^{2}[(n+2) \lambda-n] \sum_{j=1}^{N} x_{j, i} \bar{y}_{j}+C^{2}(1-\lambda) \sum_{i=1}^{n} \sum_{j=1}^{N} x_{j, i} \bar{x}_{j}-2 \lambda C \sum_{j=1}^{N} x_{j, 0} \bar{y}_{j}\right\} \\
b_{i}=\frac{C}{N} \sum_{j=1}^{N} x_{j, i} \bar{y}_{j}, b_{i j}=\frac{C^{2}}{N \lambda} \sum_{u=1}^{N} x_{u i} x_{u j} \bar{y}_{u}
\end{gathered}
$$


where $N_{w}$ - the number of points on a radius sphere $P_{w} ; k$ - sphere number $(k=3)$.

Check of coefficient significance is conducted by t-Student's test.

Estimates of the coefficients variance are calculated according to the formulas

$$
S_{b_{0}}^{2}=\frac{2 A \lambda^{2}(n+2) S_{y}^{2}}{N P}, S_{b_{i}}^{2}=\frac{A[(n+1) \lambda-(n-1)] C^{2} S_{y}^{2}}{N P}
$$

Check of the model adequacy is based on the use of Fisher's method [16].

The proposed experimental plan for the simulation model is used to solve the problem of optimizing the components delivery, which has internal contradictions. In terms of customers (industrial areas) it is profitable to assign more vehicles of increased capacity. For the transport link it is economically feasible to carry out the transportation of the smallest possible amount of vehicles.

As a compromise criterion it is proposed to use a minimum of reduced expenditures (E), which is the value of loss of waiting time and Auto-Transport Enterprise costs $\mathrm{E}_{\text {ATE }}$ on transport facility operation, i.e., $E \min =\left(T_{\Sigma} C+E_{\text {ATE }}\right)$, where $T_{\Sigma}-$ the total cost of the waiting time of all components; $C$ - cost estimate of waiting loss. In expanded form, this criterion can be written as

$$
E=\min \left(\sum_{i=1}^{l}\left(\sum_{j=1}^{m} T_{e x i} S_{j i}\right) \cdot 60 t_{i} C+E_{A T E}\right)
$$

where: $m$-number of areas; $T_{\text {exji }}$ - the average loss due to the expectation of appropriate component in the $i$-period of time; $S_{j i}$-the intensity of the applications for the component transportation on the $j$-site in the $i$-period of time. All variables expressions are counting functions and tonnage of the vehicle.

The problem of motive power selection is under the condition, when vehicle capacity $(V)$ is selected from a predetermined number of fixed values $[14,15]$.

A special feature of this approach is to examine the capacity and amount of vehicles $(N)$ as the independent variables, i.e., both of these 
parameters are calculated on the basis of the available flows of applications for moving of components.

To solve the optimization problem we propose to use numerical methods based on the search engine optimization [4]. Algorithmic diagram of the motive power selection is shown in Figure 4.

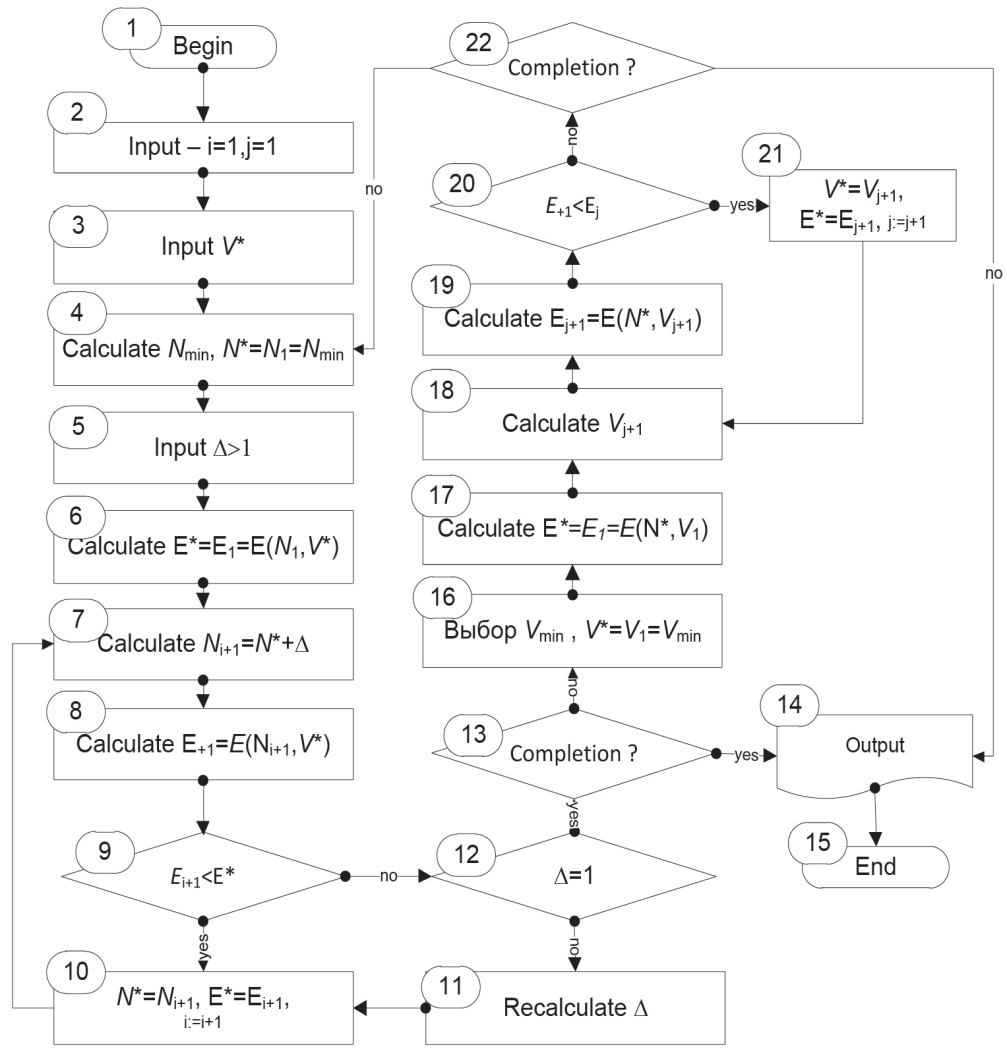

Fig. 4. A generalized diagram of the vehicle number and optimization of their capacity

The ideal case is when it is possible to select and use in different periods of time (depending on the intensity of the application flows for moving of components) the transport facilities of different sizes and 
in the required quantity. However, in most cases it is not possible to change the rolling stock. If such a possibility appears, the optimization is carried out for each such period. Therefore, taking into account the different needs of moving parts in time, modification of the above described algorithm was developed, in which the capacity of the vehicle is selected constant during the operating time and the number of the vehicle is differentiated by a predetermined time period (Figure 5).

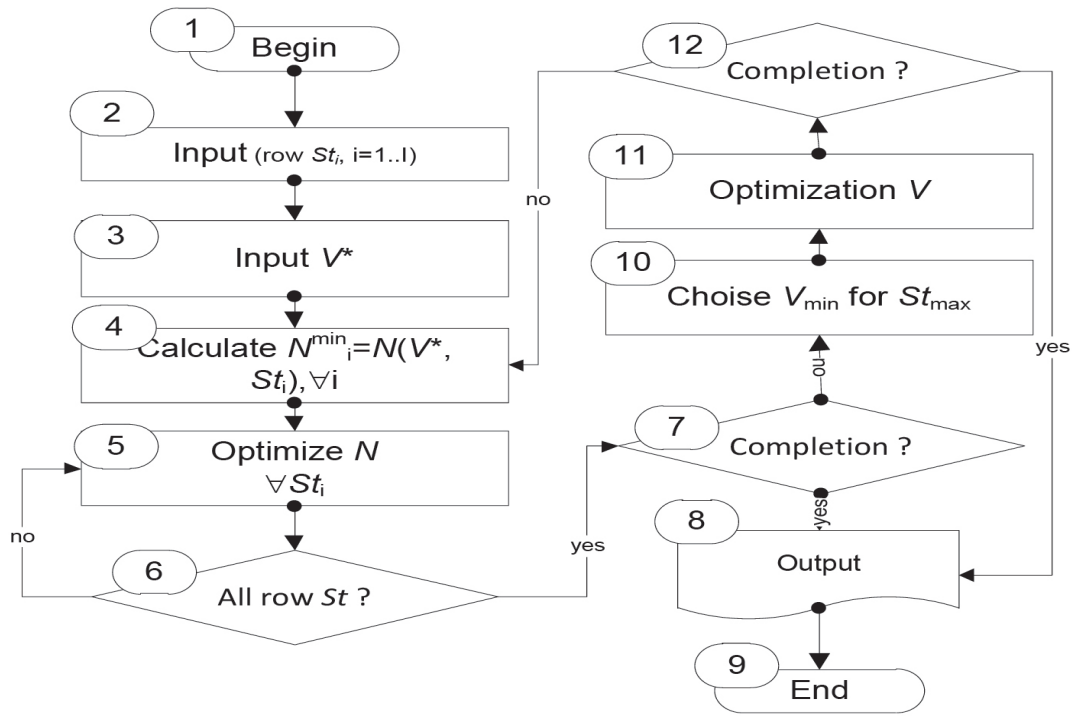

Fig. 5. The algorithm scheme of vehicles quantity optimization and their increased capacity

Block 4 calculates the minimum number of the vehicle at a given capacity for each stationary period of passenger traffic flow. Block 5 optimizes the vehicle number of this capacity for the next stationary period of applications flow for moving the components on the basis of the operations provided in blocks 5-12 of scheme shown in Figure 4. Block 10 implements a choice of minimum allowable capacity of a given number of capacities under the number of vehicles, corresponding to the intense flow stationary period. 
In block 11 the capacity optimization is performed for the most intense flow stationary period of applications for the movement of components on the basis of the operations provided in blocks 17-21 of scheme shown in Figure 4.

Each iteration process includes the optimal capacity of the vehicle, corresponding to the most intense period, and then it determines the optimal vehicle quantity of this capacity for each of the periods.

The condition for ending the decision making search in this case is found by coincidence of vehicle cargo capacity and the vehicle quantity for each of the periods on current and previous iteration.

\section{Conclusion}

Therefore, basic systematization of production functions of repair activities network and the list of planning and control functions, described in the form of business processes (BP), were made. The formal description of BP "Planning, accounting and control of movement of components", allowing you to create a work schedule of vehicle, is offered for transport-level repair facility. There is a simulation model of the movement of components under probabilistic uncertainty that allows us to estimate the vehicle congestion on the route depending on the intensity of the input stream and the average number of sections of the production repair activity network. The statistical analysis of the needs of different groups of components and accessories categories was conducted according to annual data for the purpose of parameterization of the simulation model. The planning procedure of the experiment on the simulation model in the conditions of non-stationary applications flow was proposed. Stages of simulation are presented in the form of static structure diagrams of classes and dynamic charts of activity states, sequence and interaction diagrams.

The problem of motive power selection is under the condition, when vehicle capacity is selected from a predetermined number of fixed values. A special feature of this approach is to examine the ca- 
pacity and number of the vehicles as the independent variables. In order to solve the optimization problem we propose the use of numerical methods based on search engine optimization.

The algorithm for selecting the composition of the vehicle based on the non-stationary applications flow for movement of components was developed.

\section{References}

1. Aleksakhin S.V. Automated control systems on the motor transport. Tutorial for higher education institutions. Moscow: Academia, 2011. 288 p.

2. Bashina O.E., Spirin A.A. General theory of statistics. Statistical methodology in studying of commercial activity. Moscow: Finance and methodology in studying of commercial activity. Statistics, 1999. 458 p.

3. Burkov V.N. Korgin N.A., Novikov D.A. Introduction to the theory of management of organizational systems. Moscow: Librokom, 2009. 264 p.

4. Wagner G. Bases of research of operations. Moscow: World, 1972. 371 p.

5. Ivakhnenko A.M., Akhokhov A.Ch. Modeling of quality control of technological processes and industrial output. Monograph// Moscow: “Tekhpoligraftsentr". 2008. 146 p.

6. Karasyov A.A., Stroganov D.V., Solntsev A.A., Yakunin P.S., Batov R.V. Influence of entry conditions and duration of modelling on characteristics of conditional and non-stationary processes//Science and education. MGTU of N.E. Bauman. Electronic journal. 2012. No. 4.

7. Karasyov A.A. Dynamic configuration of system of imitating modelling / Karasyov A.A., Prikhodko L.V., Falcon A.A., Yartsev M.I. // Imitating modelling of control systems. M.: MADI, 2012, pp. 7-12.

8. Nikolaev A.B., Monitoring and modelling of operating modes of transport and technological machines / Nikolaev A.B., Pashayev M.Ya., Smirnov S.Yu., Atayeva S.K. // In the world of discoveries. 2015. No. 6 (66), pp. 9-18.

9. Nikolaev A.B., Stroganov V. Yu. Automated information processing systems and controls on the motor transport; the textbook for second- 
ary vocational education. Under the editorship of A.B. Nikolaev. Moscow: Publishing centre "Academy", 2003. 224 p.

10. Nikolaev A.B. Analitiko-simulation modeling of technological processes of production, service and repair of road-building technique: Monograph / Nikolaev A.B., Dyomin V.A., Eskova I.A., Okunkova A.A., Prikhodko M.V. // Saint-Louis, MO, USA: Publishing House Science and Innovation Center, 2014. 242 p. ISBN 9780615671277

11. Nikolaev A.B. Automation of planning and control in construction and on transport. Volume 1. Automation of planning when building distributive objects: Monograph / A.B. Nikolaev, A.Ch. Akhokhov, D.V. Zaytsev, S.N. Satyshev, V.Yu. Stroganov. Saint-Louis, Missouri, USA: Publishing House Science and Innovation Center, 2015. 330 p. ISBN 978-0-615-67148-2

12. Nikolaev A.B. Automation of planning and control in construction and on transport. Volume 2. Control automation information software: Monograph / A.B. Nikolaev, B.V. Sakun, A.A. Solntsev, P. A. Timofeev, L.A. Hvoinsky. Saint-Louis, Missouri, USA: Publishing House Science and Innovation Centre, 2015. 436 p. ISBN 978-0-615-67148-2.

13. Nikolaev A.B., Demin V.A., Eskova I.A., Prikhodko M.V. Using multilevel simulation models of regenerating processes when evaluating rhythmicity of production processes//International journal of advanced studies: Publishing House Science and Innovation Centre, Ltd. (St. Louis). ISSN: 2328-1391. No.: 3 (3), 2013, pp. 10-16.

14. Nikolaev A.B. Ismailov A., Lvova A., Ostroukh A.V. Organization and Management of Transport Provided for the Guests and Participants of the Olympic Games // Middle-East Journal of Scientific Research. 2013. Vol. 17 (8), pp. 1098-1104.

15. Nikolaev A.B., Prikhodko V.M., Stroganov V.Y., Tregubov P.G. Tools of production and logistics support life cycle of high-tech products// Life Science Journal 2014; 11 (10s), pp. 238-242.

16. Shannon R. Imitating modeling of systems - art and science. M.: World, 1978. $655 \mathrm{p}$. 


\section{DATA ABOUT THE AUTHORS}

Stroganov Victor Yurievich, Laureate of the Government Prize of the Russian Federation, Doctor of Technical Sciences, Professor of the Department «Systems of information processing and management»

Moscow State Technical University - National Research University of Engineering and Technology

5, 2-ya Baumanskaya, Moscow, 105005, Russian Federation str.madi@mail.ru

Faddeeva Ekaterina Yurievna, Candidate of Technical Sciences, Associate Professor

Moscow Automobile and Road Construction State Technical University (MADI)

64, Leningradsky prospekt, 64, Moscow, 125319, Russian Federation

jointlab@mail.ru

Sakun Boris Vladislavovich, Candidate of Technical Sciences General Society with limited liability "TSM" 26 a, Khamovnichesky Val, Moscow, 119048, Russian Federation

info@tsm-msk.ru

Satyshev Sergey Nikolaevich, Candidate of Technical Sciences, Associate Professor of the Department «Organization and traffic safety»

Moscow Automobile and Road Construction State Technical University (MADI)

64, Leningradsky prospekt, 64, Moscow, 125319, Russian Federation

satmadi@mail.ru 